\title{
Urgences
}

\section{La rocaille en octobre}

\section{Claudine Richetin}

Numéro 16, mars 1987

D.G. Jones : d'un texte, d'autres

URI : https://id.erudit.org/iderudit/025403ar

DOI : https://doi.org/10.7202/025403ar

Aller au sommaire du numéro

Éditeur(s)

Urgences

ISSN

0226-9554 (imprimé)

1927-3924 (numérique)

Découvrir la revue

Citer ce document

Richetin, C. (1987). La rocaille en octobre. Urgences, (16), 80-81.

https://doi.org/10.7202/025403ar d'utilisation que vous pouvez consulter en ligne.

https://apropos.erudit.org/fr/usagers/politique-dutilisation/ 


\section{Claudine Richetin LA ROCAILLE EN OCTOBRE}

Sous la pluie, ruines fantômes

comme

une sépulture pour fleurs

là se mêlent les couleurs

des feuilles tombées. Pourtant

ce sont les pierres qui fleurissent

comme en un ramassis de livres

où les voix disparues

prolongent leurs discours

Déjà ma bouche

est pleine de pierres

Déjà les ossements de mes amis poètes

ressemblent à des fleurs

pot-pourri, paradis

Angkor Wat

ou centre-ville après

dix heures du soir? Sûrement

ni vivant ni mort

ni humain. Je passe près de là sous la pluie, sombrement. C'est une plantation de runes.

La seule contrainte que je me sois fixée est de tenter de traduire le "niveau" de langue, mais c'est une notion toute relative, dans la mesure où les choix de départ de l'auteur ne sont pas forcément basés sur des critères d'effet, alors que les miens le sont.

La poésie de Jones est tellement pour moi liée à son environnement, à son paysage intérieur (que forcément j'imagine et ne perçois que de l'extérieur, sous forme de réalités concrètes, d'éléments naturels, en relation avec la perception que j'ai de lui) que j'ai immanquablement lu et ressenti son poème en me projetant malgré moi à North Hatley, dans le jardin, et que les feuilles tombées ou les pierres ne peuvent être 
que celles que j'y ai vues. C'est là ma faiblesse, car peut-être elle réduit ce poème à quelque chose de personnel. Et je ne savais plus si c'étaient des cailloux ou des pierres qu'il aurait vus, car je n'ai jamais défini North Hatley dans ma tête autrement qu'en anglais.

Lorsque je lis un poème de Jones, celui-là ou tant d'autres, comme "The Stream Exposed With All Its Stones", ou «A Problem of Space», pour ne citer que ceux-là, je ne ressens pas seulement le sens des mots et leur musique, mais je crois percevoir une démarche qui irait toujours de l'objet à l'idée (à la manière des poèmes chinois). Et c'est particulièrement vrai dans ce poème-ci. N'est-ce pas caractéristique de passer de la pierre au livre, au mot, au caractère, à l'idée?

Et voilà une des premières difficultés rencontrées: comment garder avec des mots français, souvent plus longs et plus lourds, ce sens épuré de la matière et lui donner une inflexion quasi abstraite? Jones a écrit un poème qui ressemble pour moi à un collier de cailloux, mais j'ai peiné à garder chaque mot libre de son voisin, et je n'y suis pas toujours parvenue. Le rythme, d'abord: la langue de Jones est simple et souvent brisée, ce rythme bref n'a pas pour moi de tonalité équivalente en français, exemple: "it is», «it is not» ne me paraissent pas du tout équivalents en son et en rythme à «c'est» ou «ce n'est pas» (surtout en fin de vers).

De plus, comme l'avait prévu Jones lui-même, les rimes ou assonances peuvent difficilement porter sur les mêmes mots, et le choix de chaque mot étant lié au sens et au rythme, la traduction oblige à dévier soit de la littéralité, soit de l'effet produit. Disons que je préférerai souvent l'effet produit. N'empêche que les familles de sons auront du mal à recouper les familles de sens. L'exemple le plus net dans le poème étant «ruin» (v. 1) et «rune» (v. 21), en écho à «rain», quelques mots plus tôt. Je n'ai pas cru devoir, pour des raisons de sens, retrouver cet écho, et pourtant je le regrette. Mais bien sûr, traduire, c'est faire une suite de choix, donc d'abandons.

Autre difficulté, toute personnelle: je déteste le mot "collègue» en français (Dieu sait pourquoi), et bien qu'en anglais il ne m'inspire pas la même répulsion je devais le remplacer, au risque de neutraliser le choix de l'auteur, sans doute volontairement quotidien, et là encore, sans doute de le dévier.

Et comment retrouver «... gone go on» (v.8) sans artificialité? Et l'équivalent existe-t-il? Il ne s'agit pas là de la nécessité d'une refiguration, mais d'un autre abandon, et en pensant à «A Little Mise en Abîme», j'ai l'impression de trahir, et non plus de traduire. 